\title{
The Study on the Gear Shifting Strategy for 2-speed Planetary Transmission of Plug-in Electric Buses
}

\author{
Li Jun-qiu ${ }^{1, a}$, Lu Meng ${ }^{2, \text { b }}$, Zhu Ya-qi ${ }^{3, c}$ \\ ${ }^{1,2,3}$ School of Mechanical and Vehicular Engineering , Beijing Institute of Technology , Beijing \\ 10081,P.R.China

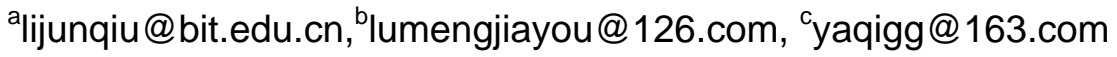

Keywords: Shift logic, Shift economy, Driving cycle, System efficiency

\begin{abstract}
The shift logic of most automatic shift systems is based on two parameters-vehicle speed and throttle opening. In this paper, two-parameter shift schedule is applied for AT. The shift logic is on the basis of the optimal efficiency of the motor-transmission system. The model is built by Simulink/Stateflow and the simulation is carried up based on the driving cycle. Driving economy can be improved significantly after applying this shift logic for the power system.
\end{abstract}

\section{Introduction}

At the moment, pure electric vehicles and plug-in electric vehicles usually use drive motors as their power source, which is matched with a transmission including a few gears to meet the acceleration and climbing conditions. As the drive motor speed is commonly very high, many problems has emerged, such as a wide speed range of the transmission, a high input speed, too few gears which enlarged the speed difference between the master and slave parts or too many gears which make the shift control system complicated. Adopting a planetary two-gears automatic transmission which is equipped with a wet clutch can overcome many commonly existed problems such as difficulties of shifting and get into gears, repeation of shifting control calibration. This system has managed to shift softly and acquire higher transmission efficiency at high gears, which make it has promising prospect.

In terms of shift performance, the shift strategy of a plug-in electric vehicle is divided into two categories: dynamic performance shift schedule and economy shift schedule. Dynamic performance shift logic is evaluated by acceleration time, while economy shift logic, which the engine is not the direct power source in a plug-in electric vehicle, is evaluated by battery energy consumption per $100 \mathrm{~km}$ with constant velocity.

Considering the driving cycle and the power system of a plug-in electric bus, based on the lowest battery energy consumption principle, this paper has designed a two-parameter shift strategy for a planetary automatic transmission. Under the same driving cycle condition, this strategy manages to decrease the battery energy consumption successfully.

\section{Structure of dynamical system}

The motor is directly connected with the planetary transmission and it adopts torque control. The correct control of the motor during the gear shifting process can realize clutch synchronization so as to reduce or eliminate shift shock.

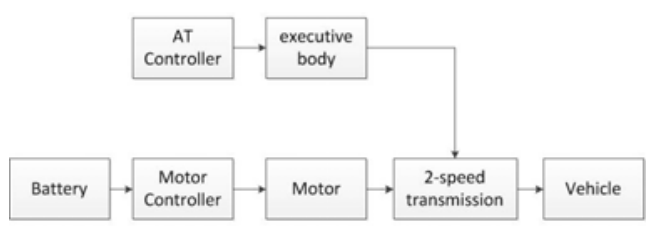

Fig.1 Structure of dynamical system

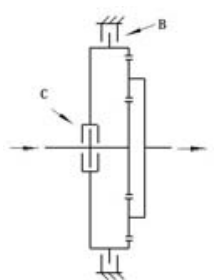

Fig.2 Structure of gearbox

Planetary automatic transmission adopted in this paper is the device which removes hydraulic torque converter with low transmission efficiency in traditional automatic transmission. It shifts by 
using wet-clutch. It has the feature of shift convenience of the planetary transmission, as well as the feature of higher shifting efficiency, compared with a traditional automatic transmission.

Automatic transmission of planet gear consists of simple planetary gear mechanism with two degrees of freedom, wet-clutch, brake and hydraulic shifting control system. As is shown in Fig.2, the transmission has two gear states. In the 1th gear, the motor is connected with the sun wheel of planetary transmission. By using brake clutch, the ring gear will be locked, so the carrier will be output of transmission. Then the planetary transmission can realize high torque output through high ratio deceleration. The transmission ratio is 3.5 .

At high speed, it transforms brake-clutch to unlock by shifting mechanism. The sun wheel and the ring wheel will connect with each other through the combination of the wet-clutch. Then the sun and ring wheels will drive the carrier rotate synchronously. So the transmission ratio is 1 .

\section{Shift principle}

\section{Dynamic performance shift logic}

Dynamic shift logic uses the speed when the two adjacent gears have the same acceleration under the same throttle opening degree as the shifting speed. If there is no point of intersection between the two adjacent gears, then the shifting speed is determined by the maximum speed under the lower gear. Figure 3 shows dynamic shift logic schematic diagram.

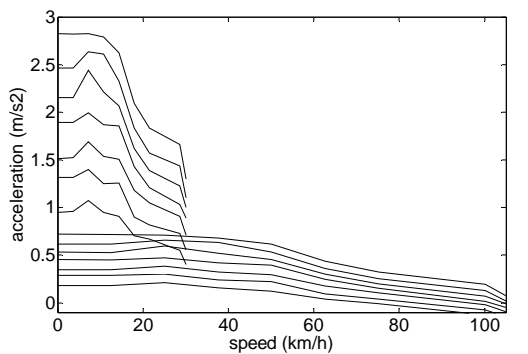

Fig. 3 Optimal dynamic shift logic

\section{The best efficiency shift logic}

As can be seen from figure 3, it is clear that there is a big shifting interval between the two adjacent gears. It's actual single-parameter shift logic if each shift speed is the highest speed of lower gear. So it is definitely unreasonable to apply the dynamic performance shift logic.

The efficiency of motor-transmission system in different speed, which can be determined from the data we get from the test on the bench, is distributed in the interval between $(0.5,0.9)$, and it have a great influence on vehicle economy which is based on consumption of battery power. As the system has different efficiency in different speed, it will lead to the non-optimal results if we just consider the efficiency of the motor. In this article, the best efficiency shift logic, under the premise of satisfying the requirement of vehicle dynamic, is determined according to the specific bus condition and the optimal efficiency performance of motor-transmission system.

Figure 4 and figure 5 show the efficiency diagram of motor - transmission system.

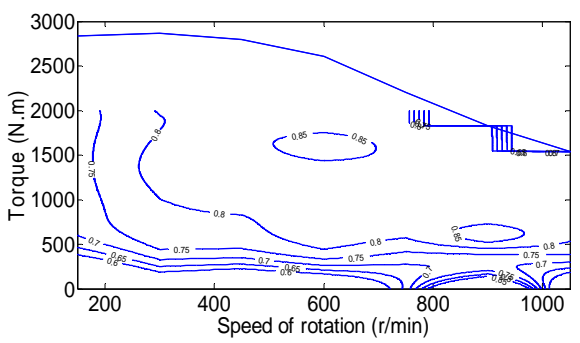

Fig.4 Efficiency-lower gear

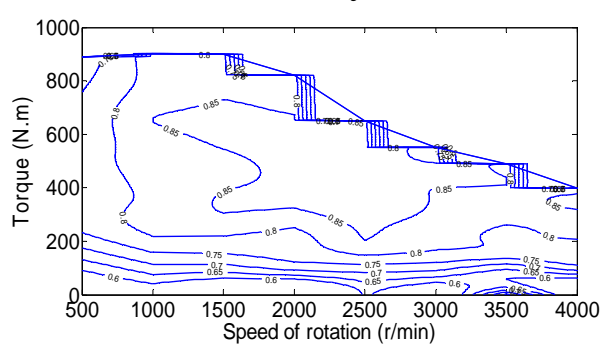

Fig.5 Efficiency-higher gear

As can be seen from the Fig6, the speed-efficiency curve, under different opening degree of accelerator, can be determined from the data we get from the test on the bench. Under the same opening degree of accelerator, the shifting strategy can be gained by joining the intersection points between the lower gear and the higher gear efficiency curve. 
In order to prevent the generation of frequent shifting phenomenon, the downshift vehicle speed is reduced $5 \mathrm{~km} / \mathrm{h}$ compared with the upshift speed.

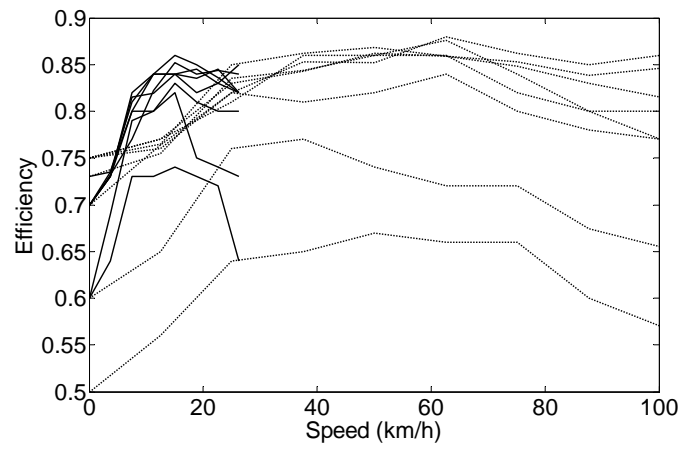

Fig.6 Efficiency at different opening degree

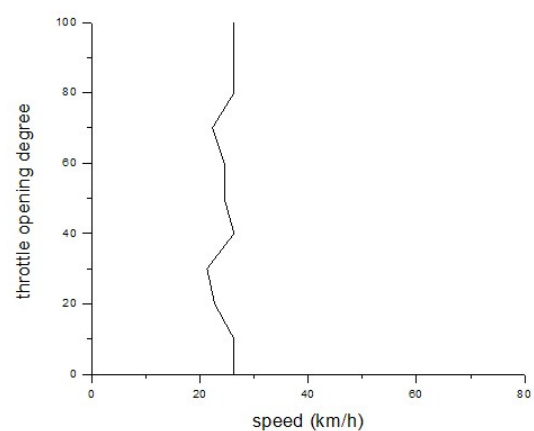

Fig.7 Shifting strategy

\section{The constraint analysis of vehicle dynamic}

Since the vehicle acceleration is confined to $0 \sim 50 \mathrm{~km} / \mathrm{h}$ in 25 seconds, therefore shifting strategy should be able to satisfy the requirements of acceleration.

The vehicle acceleration time can be calculated according to the following formula.

$$
t=\int_{u_{a 1}}^{u_{a 2}} \frac{1}{j_{a}} d u_{a}
$$

Calculating for the vehicle acceleration performance according to the figure 7 , the acceleration curve can be gained. As can be seen from the figure 8, the vehicle acceleration is $0 \sim 50 \mathrm{~km} / \mathrm{h}$ in 20 seconds, which can really satisfy the requirement of complete vehicle dynamic.

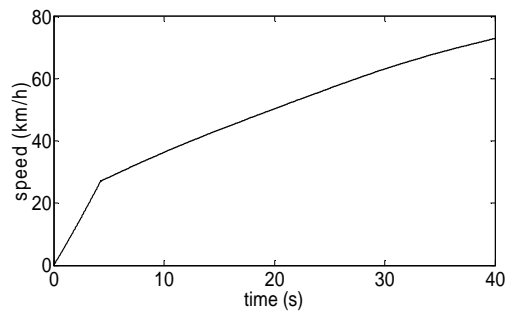

Fig.8 The acceleration curve

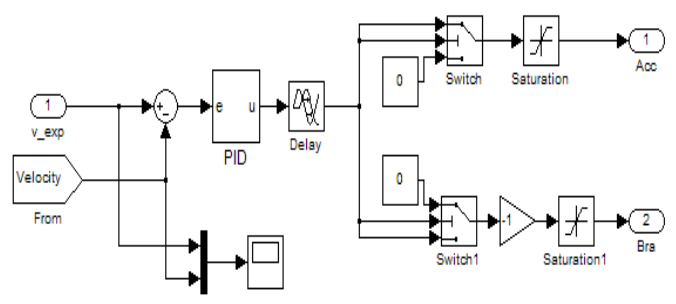

Fig.9 Driver model

\section{Model establishment}

\section{Driver model}

As is shown in Fig 9, the model adopts forward simulation. The driver model is essentially a speed controller, which is able to achieve a good speed following by using simple PID control.

\section{Vehicle model}

Vehicle power system model is combined with the driver model, shifting model, motor and gearbox model, which is shown in Figure 9.

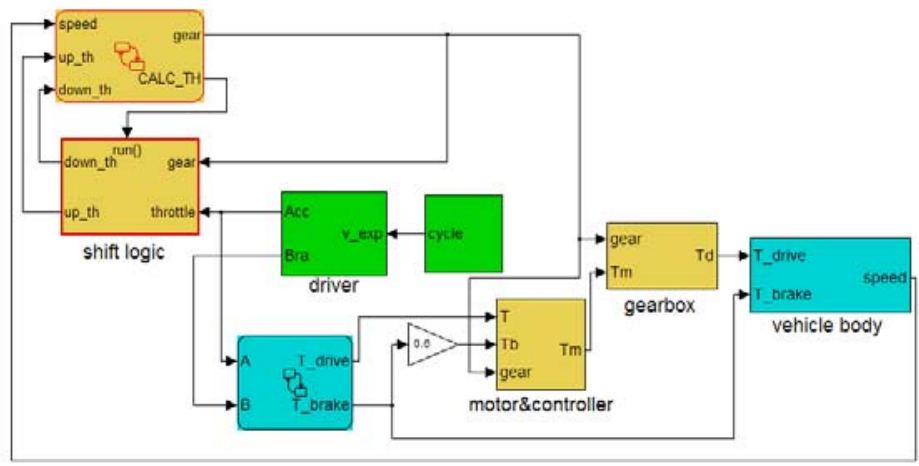

Fig 10 Vehicle model 
The main parameters are listed as below.

Table 1 Vehicle parameters

\begin{tabular}{cl}
\hline item & value \\
\hline Curb Weight(kg) & 14500 \\
Transmission Ratio & $\mathrm{i}_{1}=1$ \\
$\mathrm{i}_{0}$ & $\mathrm{i}_{2}=3.5$ \\
Tire radius $(\mathrm{m})$ & 6.5 \\
Frontal area $\left(\mathrm{m}^{2}\right)$ & 0.432 \\
\hline
\end{tabular}

\section{Simulation Analysis}

By creating M-file in Matlab, the vehicle power system model is set by the given parameters. The simulation which is based on the Nuremberg conditions, is set to 1084 seconds for the simulation time.

Figure 11 shows the comparison between the target vehicle speed and actual vehicle speed. The driver can follow the target vehicle speed accurately from Fig11.Fig12 is the map of gear state. The transmission can switch between high-gear and low-gear under the working condition, which can meet the needs of different working conditions for the vehicle.

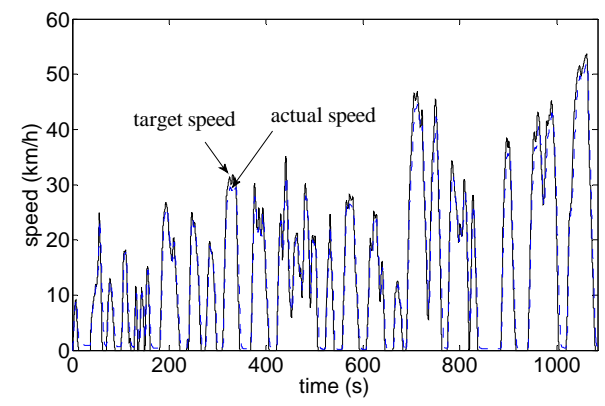

Fig.11 Driving cycle

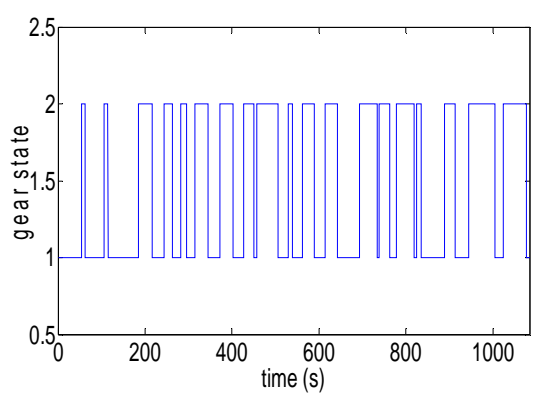

Fig.12 Gear state

Figure 12 shows the entire mileage- $4.25 \mathrm{~km}$, which is under the NurembergR36 driving cycle. Fig 14 shows the electricity consumption curve of power battery. In the vehicle testing process, it applies single-parameter shift logic, the shift points to the $15 \mathrm{~km} / \mathrm{h}$ (upshift), $10 \mathrm{~km} / \mathrm{h}$ (downshift). The energy consumption of the unit mileage for the vehicle will be significantly higher because of the single-parameter shift logic cannot control of the efficiency of the power system reasonably and effectively. Can be seen from Figure14, the battery energy consumption which applies single-parameter shift logic is 5.15kwh. While the battery energy consumption which applies shift strategy based on the optimal efficiency for power system is $3.73 \mathrm{kwh}$ in the case of the same mileage.

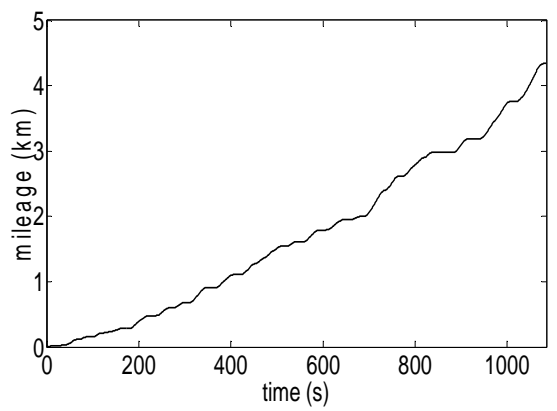

Fig.13 Distance under whole cycle

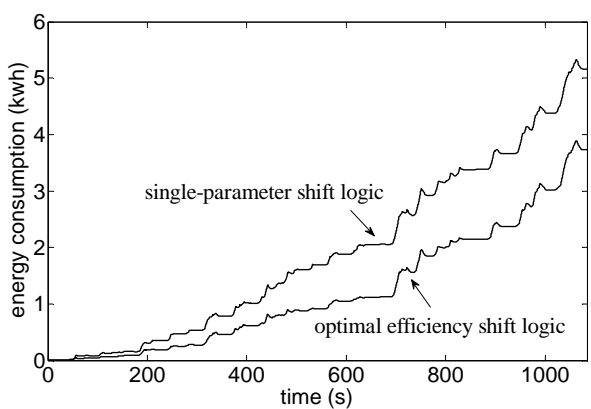

Fig.14 Comparison of different shift strategies

\section{Conclusion}

Based on the analysis of the vehicle power system, we formulate the economy dual parameter shift law based on the optimal efficiency of power system. This law can improve the operation 
efficiency of power system, and it's a good balance between the efficiency and vehicle dynamic. It's a good shift strategy solution for the electric vehicle with a two-gear automatic transmission.

Simulation result concerning vehicle economic performance shows that the energy consumption of vehicle which adopts the shift logic based on the optimal efficiency of the power system is $0.88 \mathrm{kwh} / \mathrm{km}$ on the whole condition. With respect to the single parameter shift law, it can reduce about $27.5 \%$ of the energy consumption.

\section{References}

[1] Green Car Congress. New two-speed electric vehicle transmission for improved performance, range and battery life [EB/OL](2009).

[2] H. Yoshimura and A.Hirako. Automated Mechnical Transmission Control. SAE Paper (1986).

[3] Che-wun hong. A Fuzzy Throttle Controller for Dynamic Driving Pattern Simulation. Int. J. of Vehicle Design. (1995).

[4] Qin Da-tong. Parameters Design of Powertrain System of Electric Vehicle with Two-speed Gearbox. Journal of Chongqing University(2011).

[5] Chang I. C. Recent Developments of Electric Vehicles and their Propulsion Systems. IEEE Aerospace and electric system magazine (1993).

[6] Greenbau J J. Light Truck Powertrain Optimization Techniques and Procedures[C]. SAE Paper (1987). 